\title{
Obesity in Lebanon: A National Problem
}

\author{
S. Mallat ${ }^{1}$ A. Gerges Geagea ${ }^{2}$, R. A. Jurjus ${ }^{3}$, A. Rizkallah'1, D. Oueidat ${ }^{4}$, M. Matar², \\ J. Tawilah ${ }^{2}$, A. Berbari1, A. R. Jurjus ${ }^{4 *}$ \\ ${ }^{1}$ Department of Internal Medicine, American University of Beirut Medical Center, Beirut, Lebanon \\ ${ }^{2}$ Department of Health Education, Lebanese Health Society, Beirut, Lebanon \\ ${ }^{3}$ Department of Anatomy and Regenerative Biology, Faculty of Medicine and Health Sciences, George \\ Washington University, Washington DC, USA \\ ${ }^{4}$ Department of Anatomy, Cell Biology and Physiology, Faculty of Medicine, American University of Beirut, \\ Beirut, Lebanon \\ Email:sm104@aub.edu.lb, alicejurjus@gmail.com, rosalynej@gmail.com, alainrizkallah@gmail.com, \\ aj00@aub.edu.lb, matarmike@hotmail.com, sooyemehr@hotmail.com, ab01@aub.edu.lb, "do06@aub.edu.lb
}

Received 30 April 2016; accepted 4 June 2016; published 7 June 2016

Copyright (C) 2016 by authors and Scientific Research Publishing Inc.

This work is licensed under the Creative Commons Attribution International License (CC BY).

http://creativecommons.org/licenses/by/4.0/

(c) (i) Open Access

\section{Abstract}

Obesity is a major health problem, because of its relationship with serious medical illnesses and significant economic consequences. This article explores various factors and variables affecting the prevalence of obesity in Lebanon, to focus public health initiatives and medical interventions in the management of obesity. This study interviewed 593 subjects, of more than 20 years, from all governorates of Lebanon. The interview covered personal and demographic data, awareness, knowledge, attitude and practices towards obesity including diet and physical activity. Males' and females' percentages were $51.6 \%$ and $48.4 \%$, respectively, and a young population profile was with $52.8 \%$ less than 40 years of age. The BMI index showed that $52.77 \%$ were obese with $70.6 \%$ males and $34.27 \%$ females. The great majority were educated. TV was the most used media outlet, 79.61\% watching daily between 1 - 4 hours. Obesity was considered as the most important health problem by $27.6 \%$ and ranking the $5^{\text {th }}$ after cancer, cardiovascular, smoking and HIV/AIDS. About two thirds considered it a risk factor for hypertension and type 2 diabetes mellitus and $80.27 \%$ for cardiovascular diseases. Interventions should include changes in diet habits whereby, approximately one third (33.5\%) drink carbonated beverages on a daily basis and $50.76 \%$ eat fast food, with a lack of awareness about daily calories intake by $75.38 \%$. About half of the population (56.32\%) walks daily for 20 minutes. Most people favored behavioral and lifestyle modifications in management rather than medications and surgery (67.79\%). This study provides baseline data regarding several aspects of an obesogenic environment, a major risk factor for several diseases including hypertension, diabetes and other non-communicable diseases. After describing the factors and variables affecting the prevalence of obesity, some suggestions for appropriate interventions are included, with the hope of reducing the health burden of obesity in Lebanon.

\footnotetext{
"Corresponding author.
} 


\section{Keywords}

\section{Obesity, Hypertension, Lebanon, Overweight}

\section{Introduction}

Obesity, determined as body fat excess, is one of the most common health problems worldwide, with more than 600 million adults affected in 2014 [1]. Defined as a body mass index (BMI) $\geq 30 \mathrm{~kg} / \mathrm{m}^{2}$, its prevalence is increasing to various extents among countries. For example, the measured prevalence of adult obesity is $31 \%$ in the United States, $15 \%$ in Canada, and ranges from 30\% to 70\% in the Eastern Mediterranean region (EMR) [2][4].

Persons with a BMI between 25 and 29.9 are considered overweight and those with a BMI of 30 and above are obese. There are 3 classes of obesity: class I (BMI 30 - 34.9), class II (BMI 35 - 39.9), and class III (BMI 40 and above) [5] [6]. BMI is calculated either as weight in pounds divided by height in inches squared multiplied by 703 , or as weight in kilograms divided by height in meters squared [6].

Most of the studies carried out to determine the prevalence of overweight and obesity in the EMR used the body mass index (BMI) as an indicator for obesity. It was concluded that overweight and obesity are a cause of concern not only among adults, but also among children and adolescents [7]-[9]. The worldwide prevalence of overweight and obesity among preschool children increased from 4.2\% in 1990 to 6.7\% in 2010 [10]. The United Nations (UN) sub-region of western Asia which includes many EMR countries, however, showed the highest prevalence of overweight and obesity; it increased from 3\% in 1990 to $14.7 \%$ in 2010 and is projected to reach $29.1 \%$ by 2020 [10]. The prevalence of obesity among adolescents in several EMR countries has also been trending up, and exceeding that reported from other parts of the world, for example over $30 \%$ of adolescents in Kuwait and Bahrain are either overweight or obese as compared to $29 \%$ in Canada, $26 \%$ in Italy and $19.7 \%$ in Netherlands [11]. This trend applies to adults as well [11] [12].

Obesity is considered a major health problem in many countries because of its high prevalence, chronicity, causal relationship with serious medical illnesses, and economical consequences. It has been demonstrated that intentional weight loss delays and improves many of the medical complications associated with obesity [2] [5] [13]. Moreover, most of these benefits begin after only modest reductions of $5 \%$ of initial body weight [2].

Changes in lifestyle, dietary habits, physical activity and the social and cultural environment are associated with the occurrence of obesity [14] [15]. It is well documented that morbidity and mortality rates increase with increase in body weight [6] [12]. Many chronic, non-communicable diseases are positively associated with obesity like type 2 diabetes mellitus in particular, hypertension, cardiovascular diseases and some forms of cancer [6] [16] [17]. These are the main causes of morbidity and mortality in most countries of the EMR [4] [14].

Dietary habits have markedly changed in this region over the last few decades [4] [18]. People are consuming more fats, cholesterol and refined carbohydrates and less polyunsaturated fatty acids and dietary fibers especially because of the shift to westernized foods [4] [14] [18] [19]. Overall, a dramatic increase in daily caloric intake coupled with a sedentary lifestyle of most EMR communities has played a key role in the rise in obesity [4] [14] [18]-[20].

Socio-demographic factors have also played a pivotal role in determining the patterns of obesity. For instance, it has been shown that men are more likely than women to be obese in all the regions of the world except in the EMR. Obesity is more prevalent in women in all countries of this region [4] [14]. In Kuwait for example, 39\% of men are obese as opposed to 53\% of women [14]. Another study done in semi-urban areas in Jordan found that $32.7 \%$ of men were obese as opposed to $59.8 \%$ of females [21]. The same trend was seen in Lebanon where the prevalence of obesity was $14.5 \%$ vs. $18.8 \%$ for men and women respectively [22].

Income is an important indicator which is strongly associated with obesity [14] [23] [24]. It was shown that in general, obesity in the EMR increased among both men and women as per capita income of the country increased [14]. In addition, employment status might be associated with obesity. In general, studies from the EMR have found that women are more affected by this variable, with working women being less likely to be overweight than nonworking women [14] [25]. For example, one study found that in Saudi Arabia 55.9\% of nonworking women were obese [14]. Another study reported that the rate of obesity in unemployed women in Ku- 
wait was $47 \%$ compared to $34 \%$ in employed women. In Saudi Arabia, the values were $79 \%$ and $53 \%$, and in Tunisia $24 \%$ and $15 \%$ respectively [4].

Education level has been found to be associated with obesity. One study done in Spain, found that an inverse relationship exists between the BMI and education levels [26]. In Jordan, around 50\% of women who had no or only elementary education are obese as opposed to around 20\% in educated women [21]. An explanation may be the fact that a difference in educational level has been established in relation to knowledge about nutrition [26].

Other factors might directly or indirectly affect the prevalence of obesity, like physical activity, calories intake, diet habits, preferred management, lack of health awareness, and cultural conditions. All these variables have not been investigated enough in the EMR in general and in Lebanon in particular. Hence, this report is a first step to explore these factors in order to guide and focus public health initiatives and medical interventions intended to prevent and control obesity in Lebanon.

\section{Methods}

This is a cross sectional study conducted on as ample consisting of 600 interviewees who are twenty years or more covering all Governorates of Lebanon according to their respective population densities. The aim of the survey was to reach $95 \%$ confidence interval ( $\pm 5 \%)$, so using Altman’s normogram for sample size calculation yielded a sample size of 600 . We achieved $98.8 \%$ (593 subjects) of this target. The data collected were coded, cleaned and analyzed using SPSSXVI.

The weight, height and waist circumference of the participants were measured. We used a questionnaire which was developed locally by the principal investigator, and covered the following: General information (i.e. location, consent, monitoring), individual characteristics and demographic data, Awareness about health problems, Knowledge and attitude towards obesity, physical activity, drinking and eating habits, obesity management.

\section{Results}

There were $51.6 \%(n=306)$ males and $48.4 \%(n=287)$ females leading to an overall male to female sex ratio equal to 1.06 . The overall average age of the population was $39.17+13.10$ years, a profile more towards a relatively young population. For example, people between 20 - 29 years constitute $29.2 \%$ and those between 30 - 39 years constitute $23.6 \%$.

More than half the respondents were married 58.68\% $(n=348)$ while almost one third were single 34.74\% (n $=206)$. Looking at these results by gender, more than two thirds of males $67.32 \%(n=206)$ are married as opposed to almost half of the females $49.48 \%(n=142)$.

In general, the respondents seemed to have a good education with a great majority of $97.47 \%(\mathrm{n}=578)$ of the population having gone to school and only $2.53 \%(n=15)$ with no schooling. Consequently, $83 \%(n=488)$ of the population were educated enough to read newspapers and magazines. Males and females seemed to have equal schooling chances with $98 \%(\mathrm{n}=300)$ vs. 97.47\% $(\mathrm{n}=278)$ respectively. The average years spent in school for the total population was $12.42 \pm 4.83$ years (i.e. passing the secondary schooling levels).

Males and females had similar proportions of employment with 51.6\% $(n=306)$ and $48.4 \%(n=287)$ respectively, and 18.7\% $(\mathrm{n}=106)$ were unemployed.

\subsection{Use of Media}

Data showed that $34.2 \%(n=203)$ of respondents read newspapers every day. However, males read daily almost twice as much as females, $43.79 \%(n=134)$ vs. $24.04 \%(n=69)$ respectively.

More than half of the respondents $(56.15 \%, n=333)$ listen to the radio every day with similar frequencies between males and females. However, TV appears to be the most widely used media outlet on a daily basis with more than ninety percent of both males and females, 93.14\% $(n=285)$ and $91.98 \%(n=264)$ respectively. In addition, 79.61\% ( $\mathrm{n}=472)$ watch TV 1 - 4 hours daily, an indication of sedentary lifestyle.

\subsection{Body Mass Index}

The overall BMI of the males and females was in the overweight range $26.37+11.12$, with males a little bit higher $(27.5+4.6)$ than females $(25.2+15.23)$. On the other hand, the desired weight was in the normal ac- 
ceptable weight range, an average of $23.83+9.41$ with $24.74+2.82$ in the males and a little less in the females $22.86+13.19$, Table 1 .

A closer look at the data shows that almost half $52.77 \%(n=313)$ of the respondents were in the overweight or obese range, with $70.6 \%(n=216)$ and $34.27 \%(n=97)$ for males and females respectively. The prevalence of obese subjects with a BMI $>30$ was $18.16 \%(n=107)$ with the percentage of males being more than double that of females, $24.86 \%(n=76)$ vs. $10.82 \%(n=31)$. There were also gender differences between different classes of obesity. 20.6\% $(n=63)$ of males have class one obesity as opposed to 3 times less in females $7.32 \%$ $(\mathrm{n}=21)$. The same trend was seen in Class II obesity with $3.28 \%(\mathrm{n}=10)$ and $1.4 \%(\mathrm{n}=4)$ for males and females respectively. This trend was reversed in Class IV obesity, Table 1.

\subsection{Awareness about Obesity Health Problems}

According to the respondents, the most important health problems in Lebanon were in decreasing order as follows: Cancer (61\%), Heart diseases (51\%), Smoking (40\%), HIV/AIDS (31.5\%), and Obesity (27.06\%) followed by Cold (18.5\%) and Allergy (15.77\%).

Adult obesity, about a quarter of the population ranked fifth after cancer, heart diseases, smoking and HIV/ AIDS. More than half (56.83\%) considered obesity both a public and an individual health problem while only $22.77 \%$ considered it only a public issue.

\subsection{Indicators of Obesity}

Results also showed that $43.34 \%(n=257)$ strongly agreed and a similar percentage of $44.69 \%(n=265)$ simply agreed that overweight is the most important indicator of obesity. Together, these two groups make up 88.03\%. On the other hand, the third $33.22 \%(n=197)$ strongly agreed and $44.37 \%(n=275)$ simply agreed to consider visceral fat as the most important indicator for obesity. Together, these two groups, amount to about $80 \%$ of the respondents.

\subsection{Knowledge of Obesity as a Risk Factor for Many Diseases}

Almost two thirds $(64.08 \%, \mathrm{n}=380)$ of the respondents knew that obesity is a major risk factor for hypertension and almost one quarter $(27.66 \%, \mathrm{n}=164)$ knew a little about it. The knowledge levels were somewhat less with Diabetes $(57.34 \%)$. However, the great majority of respondents $(80.27 \%, n=476)$ knew that obesity has a negative impact on cardiac diseases, but much less on cancer (18.04\%), Table 2.

Near half the people did not know of any effect of obesity on cancer $(48.56 \%(n=288))$. Finally, most respondents either did not know or considered obesity to have a little effect on dementia, Table 2.

\subsection{Public Interventions to Control Obesity}

Data showed that almost 2/3 of the respondents strongly supported a media campaign $(68.13 \%(n=404)$ ), school health education $(67.45 \%(n=400))$ and more sports at schools $(68.46 \%(n=406))$ to face the risks of obesity. Only a percentage of $5 \%$ or less was against all these interventions. Consequently, more than $95 \%$ supported government and public interventions to deal with obesity.

Table 1. Actual and desired BMI categories.

\begin{tabular}{|c|c|c|c|c|c|c|c|c|c|c|c|c|c|c|c|c|}
\hline \multirow{2}{*}{\multicolumn{2}{|c|}{$\begin{array}{c}\text { BMI } \\
\text { Categories }\end{array}$}} & \multicolumn{2}{|c|}{$<18.5$} & \multicolumn{2}{|c|}{$18.5-24.9$} & \multicolumn{2}{|c|}{$25-29.9$} & \multicolumn{2}{|c|}{$30-34.9$} & \multicolumn{2}{|c|}{35 - 39.9} & \multicolumn{2}{|c|}{$\geq 40$} & \multicolumn{2}{|c|}{ Total Average } & \multirow{2}{*}{$\begin{array}{c}\text { Population } \\
\text { Average }\end{array}$} \\
\hline & & $\mathrm{M}$ & $\mathrm{F}$ & M & $\mathrm{F}$ & M & $\mathrm{F}$ & M & $\mathrm{F}$ & M & $\mathrm{F}$ & M & $\mathrm{F}$ & M & $\mathrm{F}$ & \\
\hline \multirow[t]{2}{*}{ Actual } & No & 1 & 12 & 89 & 174 & 140 & 66 & 63 & 21 & 10 & 4 & 3 & 6 & $27.5 \pm 4.6$ & $25.2 \pm 15.2$ & $26.4 \pm 11.1$ \\
\hline & $\%$ & 0.3 & 0.2 & 29.1 & 60.6 & 45.8 & 23 & 20.6 & 7.3 & 3.3 & 1.4 & 1 & 2.1 & & & \\
\hline \multirow[t]{2}{*}{ Desired } & No & 4 & 18 & 169 & 237 & 123 & 22 & 6 & 3 & 2 & 1 & 0 & 2 & $24.7 \pm 2.8$ & $22.9 \pm 13.2$ & $23.8 \pm 9.4$ \\
\hline & $\%$ & 1.3 & 6.3 & 55.2 & 82.6 & 40.2 & 7.7 & 2 & 1.0 & 0.7 & 0.4 & 0 & 0.7 & & & \\
\hline
\end{tabular}




\subsection{Beliefs about Personal Lifestyle, Heredity and Environment}

Almost half of the population $(49.7 \%, n=295)$ believed that diet and body activity determine obesity, while $30 \%$ chose heredity and genetic background, and $20 \%(n=119)$ chose the environment. Hence, diet and body activity equaled the sum of all the other parameters put together without any significant difference between the males and females about these issues.

\subsection{Daily Continuous Walking Duration}

More than half of the respondents $(56.32 \%, \mathrm{n}=437)$ walk continuously for more than 20 min per day, $21.41 \%$ $(\mathrm{n}=127)$ walk for $20-30$ min and about $34.91 \%(n=207)$ walk continuously for more than 30 min. The average walking time per person was more than 15 - 20 min a day. Male percentages are higher for the longest duration of more than 30 min while Females are found in higher percentages for short walking durations, up to 20 min, $40.1 \%(n=125)$ vs. $28.57 \%(n=82)$ for males and females respectively, Table 3 .

\subsection{Diet}

One third of the respondents $(33.5 \%, \mathrm{n}=199)$ reported drinking carbonated beverages on a daily basis, the greatest majority of them take one or two drinks $21.92 \%(n=130)$ and $8.6 \%(n=51)$ respectively, while the rest $(3.05 \%, \mathrm{n}=18)$ take 3 to 7 beverages a day. The intake of diet beverages is higher in females than males $(28.91 \%, n=83)$ vs. $15.03 \%(n=46)$ respectively.

More than half the respondents $(50.76 \%, \mathrm{n}=301)$ reported not eating fast food, almost equally divided between males $49.34 \%$ and females $52.26 \%$. As for those who eat fast food, $23.1 \%(n=137)$ do so at least once a week.

The greatest majority $(75.38 \%, \mathrm{n}=447)$ did not know their daily calories intake, with slightly more in males than females, $79.41 \%(n=243)$ vs. $71.08 \%(n=204)$ respectively.

Table 2. Knowledge about obesity as a risk factor for diseases.

\begin{tabular}{ccccccc}
\hline \multirow{2}{*}{ Category } & \multicolumn{2}{c}{ A little } & \multicolumn{2}{c}{ A lot } & \multicolumn{2}{c}{ Do not know } \\
\cline { 2 - 7 } & $\%$ & No. & $\%$ & No. & $\%$ & No. \\
\hline Hypertension & 27.66 & 164 & 64.08 & 380 & 8.26 & 49 \\
Diabetes & 27.15 & 161 & 57.34 & 340 & 15.51 & 92 \\
Cardiac diseases & 16.02 & 95 & 80.27 & 476 & 3.71 & 22 \\
Cancer & 33.39 & 198 & 18.04 & 107 & 48.56 & 288 \\
Dementia & 27.82 & 165 & 5.9 & 35 & 66.38 & 393 \\
\hline
\end{tabular}

Table 3. Daily continuous walking duration.

\begin{tabular}{ccccccc}
\hline \multirow{2}{*}{ Time category } & \multicolumn{2}{c}{ Total population } & \multicolumn{2}{c}{ Males } & \multicolumn{2}{c}{ Females } \\
\cline { 2 - 6 } & No. & $\%$ & No. & $\%$ & No. & $\%$ \\
\hline 5 min & 46 & 7.75 & 19 & 6.2 & 27 & 9.47 \\
$5-10$ min & 48 & 8.1 & 20 & 6.5 & 28 & 9.75 \\
$10-15$ min & 62 & 10.45 & 29 & 9.47 & 33 & 11.5 \\
$15-20$ min & 99 & 16.7 & 45 & 14.70 & 54 & 18.81 \\
$20-30$ min & 127 & 21.41 & 65 & 21.24 & 62 & 21.6 \\
$>30$ min & 207 & 34.91 & 125 & 40.1 & 82 & 28.57 \\
N/A & 4 & 0.6 & 3 & 0.98 & 1 & 0.35 \\
Total & 593 & 100 & 306 & 100 & 287 & 100 \\
\hline
\end{tabular}




\subsection{Preferred Weight Loss Methods}

Most people favored behavioral and lifestyle modifications rather than medications or surgical interventions. When asked about what they would do to control their weight, most of the respondents were in favor of diet and exercise (67.79\% and 67.3\% respectively) over other options, Table 4.

\section{Discussion}

This study provides baseline data in Lebanon regarding several aspects of obesity, which impairs the quality of life and is emerging as a major risk factor for several diseases of public health significance like hypertension, diabetes, heart disease and several types of cancer [6] [12] [16] [17] [27] [28].

The results from this national population-based study showed that the average BMI of the total population is in the overweight category $26.37+11.12 \mathrm{~kg} / \mathrm{m}^{2}$ with males having slightly higher weights than females (27.5 $\mathrm{kg} / \mathrm{m}^{2}$ vs. $25.2 \mathrm{~kg} / \mathrm{m}^{2}$ respectively). This is consistent with previously published data and constitutes a warning sign that must be seriously dealt with before reaching more severe levels [22] [29]-[33].

The prevalence of overweight in the population is $53.5 \%$, with more males in this category than females $(70.6 \%$ vs. $34.27 \%$ respectively). In addition, the prevalence of obesity is $18.16 \%$ based on a BMI of $>30$ with more obese males than females ( $24.86 \%$ vs. $10.95 \%$, respectively). However, the trend of having more overweight and obese males than females is opposite to that reported from Lebanon and most neighboring countries in recent years [4] [14] [21] [22]. One of the reasons might be a higher proportion of single women in Lebanon compared to neighboring countries. This could contribute to lower rates of obesity in Lebanese women since single women are more likely to be employed, and employment has been associated with lower weight, because of a more active lifestyle [25] [26]. This coupled with our sociocultural trends that associate slenderness with good looks, as opposed to neighboring countries where "plumpness" is considered healthy and attractive [22], might play an additional role in the lower incidence of obesity seen in Lebanese women. Our data show that the percentages of single and employed Lebanese women are $41.46 \%$ and $48.4 \%$ respectively, however data from neighboring countries is lacking hence more studies are needed for comparison.

Another finding in our survey was the dissatisfaction of the respondents with their present state and their desire to have a lesser weight, which forms the basis for the calculation of the desired body mass index (DBMI) which is $23.83+9.41 \mathrm{~kg} / \mathrm{m}^{2}$ for the whole population, with a higher DBMI in males than females $(24.74+2.8$ $\mathrm{kg} / \mathrm{m}^{2}$ vs. $22.86+13.19 \mathrm{~kg} / \mathrm{m}^{2}$, respectively). This desire to have a lower BMI which is within the normal range seems promising from public health and medical perspectives since it might indicate that this population will readily accept interventions to prevent and control obesity.

Awareness is essential in fighting obesity, and mass media exposure may be considered of special relevance because it does help in campaigns to reach the largest possible portion of the population, since TV is watched by more than $90 \%$ of the Lebanese people. Health programs on TV's are generally popular. Hence this media outlet should be used to a greater extent by future health education campaigns related to obesity. The respondents know partly about the seriousness of obesity as a very important health issue. They consider it as the most important health issue only after four other important problems in a decreasing order: cancer, cardiovascular diseases, smoking and HIV/AIDS. In addition, a number of subjects don't consider adult obesity a health problem

Table 4. Preferred methods of weight loss.

\begin{tabular}{lcccccc}
\hline \multirow{2}{*}{ Category } & \multicolumn{2}{c}{ Total (Yes) } & \multicolumn{2}{c}{ Males (Yes) } & \multicolumn{2}{c}{ Females (Yes) } \\
\cline { 2 - 7 } & No. & $\%$ & No. & $\%$ & No. & $\%$ \\
\hline 1) Diet to lose weight & 402 & 67.79 & 219 & 71.57 & 183 & 63.76 \\
2) Exercise & 399 & 67.3 & 211 & 68.95 & 188 & 65.51 \\
3) Hypnotherapy & 37 & 6.3 & 15 & 4.9 & 22 & 7.67 \\
4) Medication use & 138 & 23.23 & 67 & 21.9 & 71 & 24.74 \\
5) Liposuction & 99 & 16.7 & 32 & 10.46 & 67 & 23.35 \\
6) Surgery (bariatric) & 43 & 7.25 & 15 & 4.9 & 28 & 9.76 \\
\hline
\end{tabular}


at all but rather a beauty problem and some even consider it only a minor problem (12.5\% and $11.88 \%$ respectively). On the other hand, the majority of the respondents know that obesity is a risk factor that increases substantially the risk of diabetes, hypertension and heart diseases (57.34\%, $64.08 \%$ and $80.27 \%$ respectively). This area should be further emphasized in awareness campaigns by stressing the negative health consequences of obesity.

Eating and drinking habits that include intake of carbonated beverages and fast foods are among the most important causes of the continuous rise in obesity. Three quarters of the respondents drink carbonated beverages with diet beverages being more popular in females than males (28.91\% vs. $15.03 \%$ respectively). In addition, almost half of the respondents eat fast food at least once a week with a quarter eating between two to six fast food meals weekly. More males consume fast food than females. These results indicate that females are more diet oriented than males which could also partly explain the difference in obesity prevalence between the two genders. Furthermore, there is a very low awareness of caloric intake by the respondents, since around three quarters of the respondents (75.38\%) could not approximate their daily caloric intake. This lack of awareness about caloric intake is surprising in an educated population, and should be much better addressed and promoted.

In line with considering obesity a public or an individual issue, the vast majority of respondents ( $95 \%)$ strongly support one of several public or governmental interventions. Hence, around two thirds (67.3\%) are strongly supportive of government-sponsored media campaigns that warn the public about the health risks of obesity. However when asked about personal parameters that determine obesity, half of the respondents believe that hereditary and environmental factors are the most important as opposed to diet and body activity. This means that a significant part of the population is passive and lacks awareness vis-à-vis modifiable determinants of obesity. Personal lifestyle factors should be further emphasized.

Professional societies recommend 150 min of brisk walking per week for people with excess fat mass, which is more than 20 min of walking per day [5] [34]. Only 56.32\% of the respondents reported walking daily for more than 20 min. Furthermore, a significant proportion of the Lebanese population watches TV for hours daily. These are indicators of a sedentary lifestyle and are major contributors to the prevalence of obesity. Hence, our population should be pushed to become much more active.

Of the several practices recommended to control and prevent obesity, the respondents preferred lifestyle modifications like diet and exercise over interventions like medications and bariatric surgery $(23.23 \%$ and $7.25 \%$ respectively). This attitude is encouraging because lifestyle modification are always the preferred first step in managing obesity before resorting to other interventions. However, it is notable that women are more supportive of liposuction and surgery to reduce weight, probably for cosmetic rather than medical reasons, since these methods yield faster results. Therefore, the long term benefits of a healthy lifestyle should be further stressed, particularly for women.

\section{Conclusion}

In conclusion, our study sheds light on several factors and variables (Figure 1) related to the prevalence of obesity

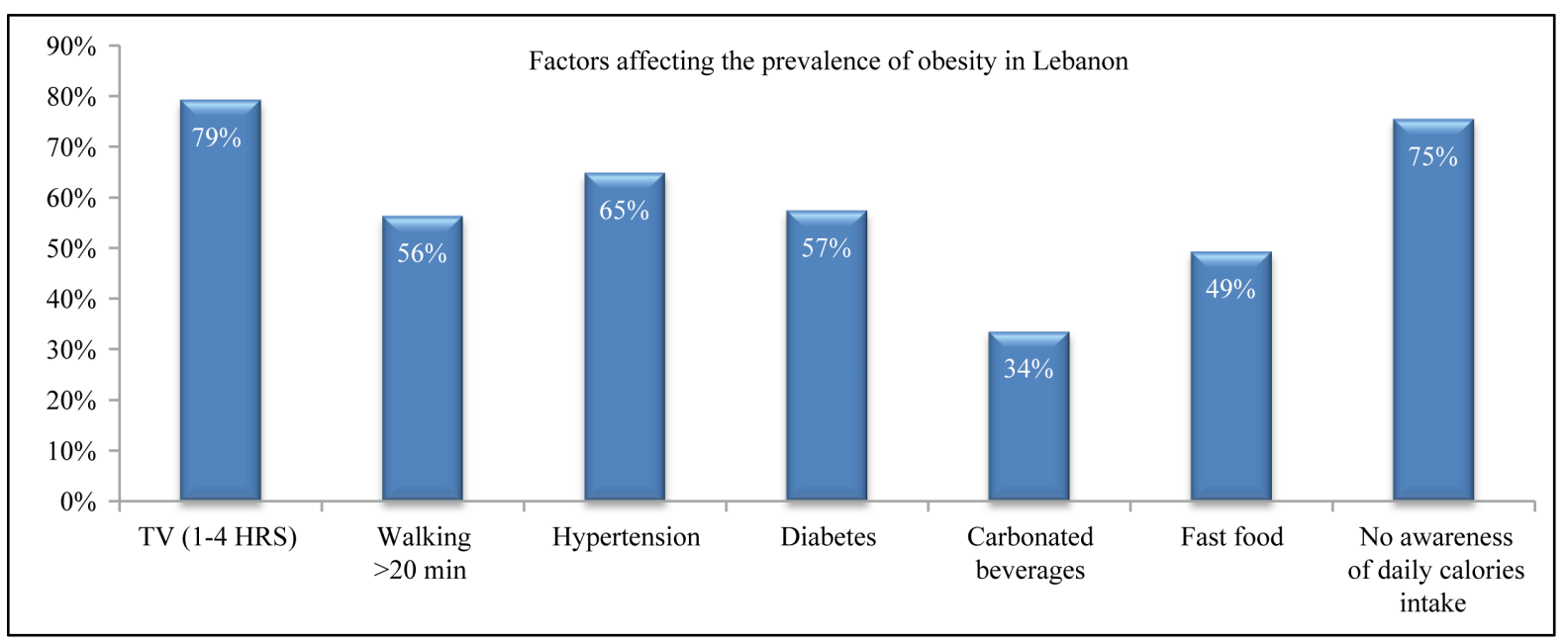

Figure 1. Factors and variables affecting the prevalence of obesity in Lebanon. 
in Lebanon and ranks this country among overweight nations. Gaps in knowledge and awareness were also identified, in addition to the interventions that are more likely to be accepted by the population. Its importance lies in its potential to direct healthcare professionals and focus their efforts to control and prevent the development of obesity and possibly identify and beat pre-existing obesity in children and adolescents, thus reducing the risk of mortality and morbidity due to non-communicable diseases and decreasing the negative psychosocial effects of obesity.

\section{Disclosure}

The authors affirm that there is no conflict of interest that could be perceived to bias the work, making know all financial support or any personal connections.

\section{References}

[1] World Health Organization, Media Centre (2015) Obesity and Overweight, Fact Sheet No. 311. http://www.who.int/mediacentre/factsheets/fs311/en/

[2] Racette, S.B., Deusinger, S.S. and Deusinger, R.H. (2003) Obesity: Overview of Prevalence, Etiology, and Treatment. Physical Therapy, 83, 276-288.

[3] Center for Disease Control and Prevention. Behavioral Risk Factor Surveillance System (2015). http://www.cdc.gov/obesity/data/adult.html

[4] Musaiger, A.O. (2004) Overweight and Obesity in the Eastern Mediterranean Region: Can We Control It? Eastern Mediterranean Health Journal, 10, 789-793.

[5] Gonzalez-Campoy, J.M., St. Jeor, S.T., Castorino, K., Ebrahim, A., Hurley, D., Jovanovic, L., Mechanick, J.I., Petak, S.M., Yu, Y.H., Harris, K.A., Kris-Etherton, P., Kushner, R., Molini-Blandford, M., Nguyen, Q.T., Plodkowski, R., Sarwer, D.B. and Thomas, K.T. (2013) Clinical Practice Guidelines for Healthy Eating for the Prevention and Treatment of Metabolic and Endocrine Diseases in Adults: Cosponsored by the American Association of Clinical Endocrinologists/the American College of Endocrinology and the Obesity Society. Endocrine Practice, 19, 1-82. http://dx.doi.org/10.4158/EP13155.GL

[6] National Institutes of Health-North American Association for the Study of Obesity (2000) The Practical Guide. Identification, Evaluation and Treatment of Overweight and Obesity in Adults. NIH Publication Number 00-4084. http://www.nhlbi.nih.gov/guidelines/obesity/prctgd c.pdf

[7] Nasreddine, L., Mehio-Sibai, A., Mrayati, M., Adra, N. and Hwalla, N. (2010) Adolescent Obesity in Syria: Prevalence and Associated Factors. Child: Care, Health and Development, 36, 404-413. http://dx.doi.org/10.1111/j.1365-2214.2009.01042.x

[8] Al-Isa, A., Akanji, A.O. and Thalib, L. (2010) Prevalence of the Metabolic Syndrome among Female Kuwaiti Adolescents Using Two Different Criteria. British Journal of Nutrition, 103, 77-81. http://dx.doi.org/10.1017/S0007114509991425

[9] Al-Isa, A.N., Campbell, J. and Desapriya, E. (2010) Factors Associated with Overweight and Obesity among Kuwaiti Elementary Male School Children Aged 6-10 Years. International Journal of Pediatrics, 2010, Article ID 459261, 6 p.

[10] De Onis, M., Blossner, M. and Borghi, E. (2010) Global Prevalence and Trends of Overweight and Obesity among Preschool Children. American Journal of Clinical Nutrition, 92, 1257-1264. http://dx.doi.org/10.3945/ajcn.2010.29786

[11] Mirmiran, P., Sherafat-Kazemzadeh, R., Jalali-Farahani, S. and Azizi, F. (2010) Childhood Obesity in the Middle East: A Review. Eastern Mediterranean Health Journal, 16, 1009-1017.

[12] Ng, S.W., Zaghloul, S., Ali, H.I., Harrison, G. and Popkin, B.M. (2011) The Prevalence and Trends of Overweight, Obesity and Nutrition-Related Non-Communicable Diseases in the Arabian Gulf States. Obesity Reviews, 12, 1-13. http://dx.doi.org/10.1111/j.1467-789X.2010.00750.x

[13] Hossain, P., Kawar, B. and El Nahas, M. (2007) Obesity and Diabetes in the Developing World—A Growing Challenge. New England Journal of Medicine, 356, 213-215. http://dx.doi.org/10.1056/NEJMp068177

[14] Musaiger, A.O. (2011) Overweight and Obesity in Eastern Mediterranean Region: Prevalence and Possible Causes. Journal of Obesity, 2011, Article ID: 407237, 17 p.

[15] Naja, F., Nasreddine, L., Itani, L., Chamieh, M.C., Adra, N., Sibai, A.M. and Hwalla, N. (2011) Dietary Patterns and Their Association with Obesity and Sociodemographic Factors in a National Sample of Lebanese Adults. Public Health Nutrition, 14, 1570-1578. http://dx.doi.org/10.1017/S136898001100070X

[16] Kuczmarski, R.J., Carroll, M.D., Flegal, K.M. and Troiano, R.P. (1997) Varying Body Mass Index Cutoff Points to Describe Overweight Prevalence among US Adults: NHANES III (1988 to 1994). Obesity Research, 5, 542-548. 
http://dx.doi.org/10.1002/j.1550-8528.1997.tb00575.x

[17] Donohoe, C.L., O’Farrell, N.J., Doyle, S.L. and Reynolds, J.V. (2014) The Role of Obesity in Gastrointestinal Cancer: Evidence and Opinion. Therapeutic Advances in Gastroenterology, 7, 38-50. http://dx.doi.org/10.1177/1756283X13501786

[18] Bin Zaal, A.A., Musaiger, A.O. and D’Souza, R. (2009) Dietary Habits Associated with Obesity among Adolescents in Dubai, United Arab Emirates. Nutricion Hospitalaria, 24, 437-444.

[19] Amin, T.T., Al-Sultan, A.I. and Ali, A. (2008) Overweight and Obesity and Their Relation to Dietary Habits and Socio-Demographic Characteristics among Male Primary School Children in Al-Hassa, Kingdom of Saudi Arabia. European Journal of Nutrition, 47, 310-318. http://dx.doi.org/10.1007/s00394-008-0727-6

[20] Al-Haifi, A.R., Al-Fayez, M.A., Al-Athari, B.I., Al-Ajmi, F.A., Allafi, A.R., Al-Hazzaa, H.M. and Musaiger, A.O. (2013) Relative Contribution of Physical Activity, Sedentary Behaviors, and Dietary Habits to the Prevalence of Obesity among Kuwaiti Adolescents. Food and Nutrition Bulletin, 34, 6-13. http://dx.doi.org/10.1177/156482651303400102

[21] Madanat, H.N., Troutman, K.P. and Al-Madi, B. (2008) The Nutrition Transition in Jordan: The Political, Economic and Food Consumption Contexts. Global Health Promotion, 15, 6-10. http://dx.doi.org/10.1177/1025382307088092

[22] Sibai, A.M., Hwalla, N., Adra, N. and Rahal, B. (2003) Prevalence and Covariates of Obesity in Lebanon: Findings from the First Epidemiological Study. Obesity Research, 11, 1353-1361. http://dx.doi.org/10.1038/oby.2003.183

[23] Bonaccio, M., Bonanni, A.E., Di Castelnuovo, A., De Lucia, F., Donati, M.B., de Gaetano, G., Iacoviello, L. and Moli-Sani Project Investigators (2012) Low Income Is Associated with Poor Adherence to a Mediterranean Diet and a Higher Prevalence of Obesity: Cross-Sectional Results from the Moli-Sani Study. BMJ Open, 2, Pii: e001685. http://dx.doi.org/10.1136/bmjopen-2012-001685

[24] Su, D., Esqueda, O.A., Li, L. and Pagan, J.A. (2012) Income Inequality and Obesity Prevalence among OECD Countries. Journal of Biosocial Science, 44, 417-432. http://dx.doi.org/10.1017/S002193201100071X

[25] Ainy, E. and Azizi, F. (2007) Women, Occupation and Cardiovascular Risk Factors: Findings from the Tehran Lipid and Glucose Study. Public Health, 121, 950-953. http://dx.doi.org/10.1016/j.puhe.2006.12.016

[26] Martin, A.R., Nieto, J.M., Ruiz, J.P. and Jimenez, L.E. (2008) Overweight and Obesity: The Role of Education, Employment and Income in Spanish Adults. Appetite, 51, 266-272. http://dx.doi.org/10.1016/j.appet.2008.02.021

[27] Amadou, A., Ferrari, P., Muwonge, R., Moskal, A., Biessy, C., Romieu, I. and Hainaut, P. (2013) Overweight, Obesity and Risk of Premenopausal Breast Cancer According to Ethnicity: A Systematic Review and Dose-Response MetaAnalysis. Obesity Reviews, 14, 665-678. http://dx.doi.org/10.1111/obr.12028

[28] Simpson, E.R. and Brown, K.A. (2013) Minireview: Obesity and Breast Cancer: A Tale of Inflammation and Dysregulated Metabolism. Journal of Molecular Endocrinology, 27, 715-725. http://dx.doi.org/10.1210/me.2013-1011

[29] Al-Isa, A.N. (1995) Prevalence of Obesity among Adult Kuwaitis: A Cross-Sectional Study. International Journal of Obesity and Related Metabolic Disorders, 19, 431-433.

[30] Al-Nuaim, A.R., Al-Rubeaan, K., Al-Mazrou, Y., Al-Attas, O., Al-Daghari, N. and Khoja, T. (1996) High Prevalence of Over-Weight and Obesity in Saudi Arabia. International Journal of Obesity and Related Metabolic Disorders, 20, 547-552.

[31] Ajlouni, K., Jaddou, H. and Batieha, A. (1998) Obesity in Jordan. International Journal of Obesity, 22, 624-628. http://dx.doi.org/10.1038/sj.ijo.0800637

[32] Musaiger, A.O. and Radwan, H.M. (1995) Social and Dietary Factors Associated with Obesity in University Female Students in United Arab Emirates. Perspectives in Public Health, 115, 96-99. http://dx.doi.org/10.1177/146642409511500207

[33] Abdul-Rahim, H.F., Abu-Rmeileh, N.M., Husseini, A., Holmboe-Ottesen, G., Jervell, J. and Bjertness, E. (2001) Obesity and Selected Co-Morbidities in an Urban Palestinian Population. International Journal of Obesity, 25, 1736-1740. http://dx.doi.org/10.1038/sj.ijo.0801799

[34] US Department of Health and Human Services (2008) Physical Activity Guidelines for Americans. United States Department of Health and Human Services, Washington DC. http://health.gov/paguidelines/pdf/paguide.pdf 